\title{
Study on Energy Saving Control of Electrical Auto- mation System for Construction Equipment
}

Huang Min Ma Lianhua

\begin{abstract}
Objective: To improve the existing problems of traditional construction equipment through electrical automation system, such as low water pressure on high floor, irrational lighting system and energy consumption of air conditioning system. Methods: The energy saving control of electrical automation system of construction equipment was studied in detail from four aspects: heat pump, variable air volume, enthalpy and lighting system. Results: The heat pump, variable air volume, enthalpy, lighting system energy saving control optimization, on the one hand to provide people comfortable and suitable for the surrounding environment, on the other hand to enhance the efficiency of building equipment control and resource utilization. Conclusion: The introduction of new technology in construction equipment is in line with China's sustainable development concept. Energy saving and environmental protection is the future development direction of the construction market and needs further exploration in the future.
\end{abstract}

Key words: Construction equipment; electrical automation system; energy saving control

\section{Introducti}

The so-called construction equipment includes water supply system, sewage system, air conditioning system, lighting system, fire safety, elevator management and other aspects, which is the main building elements for the building and can be considered as blood and muscle of a building. The construction equipment electrical automation system refers to all the local control system through all the construction equipment into a whole control

Chongqing Vocational and Technical College of Safety and Technology, Chongqing 404020 platform of the all-round system. It can be combined with the surrounding environment changes, equipment, such as the use of automatic control of the working conditions of construction equipment to ensure that all equipment work optimization; it can monitor the work of the equipment, timely feedback work data, adjust its work mode; it can solve Similar to the trip power outages, outsiders invade and other common accidents, comprehensive regulation of water and other resources to provide a full range of automated control and management.

\section{Study on Energy-saving Control of ater Source Heat Pump and Ground Source Heat Pump}

Generally speaking, the air conditioning system in the building has high installation costs, high energy consumption, high daily maintenance costs, in which electrical automation system is one of the core monitoring objects. At present, the control point for the air conditioning system is far more than other construction equipment, its power consumption is far greater than other construction equipment, we can see from the air conditioning system of energy control research is an inevitable trend.

The so-called water source heat pump is based on the differences between the surface water temperature and the temperature of the building in different seasons, that is, the summer water temperature is lower than the building temperature, the winter is the opposite, and the water temperature is relatively stable. Therefore, the engineering point of view, the water source for the media with the heat pump to achieve building temperature or cooling, and then achieve the air temperature control objectives.

The so-called ground source heat pump, also known as a soil-coupled heat pump, which is widely used in building air conditioning systems. The actual operation is: through the pipeline buried form, and the water for the hot and cold conversion medium, which buried in the soil heat transfer pipe and 
heat pump components between the flow of heat, so as to achieve heat pump components and soil heat between. In fact, the rapid development of the technology in recent years, has been in the Western countries tend to improve, but China is still in the late development.

Compared with the traditional air conditioning system, water source, ground source heat pump technology is significant:

High efficienc, less energy consumption

The relevant data show that the soil layer absorbs nearly half of the heat of solar radiation, and can guarantee the balance of heat absorption and distribution, so the soil layer temperature is relatively stable. In addition, the use of renewable resources, high efficiency, low energy consumption, which to meet the concept of sustainable development.

High functionality, wide application

The whole system as long as a device, the hot weather when the cold, cold weather when the heat, so the system is relatively simple, including heat pump parts, refrigeration components, in addition to widely used in large shopping centers, office buildings, residential and other places of life which is also in this way.

Safety and environmental protection

The whole system does not exist spontaneous combustion, exhaust or electromagnetic interference and a series of problems, energy transmission is also limited to close distant, so the environmental effect is obvious.

\section{Stable operation}

The whole system is relatively stable and safe operation, which is not easily affected by the external envi- ronment. In the case of consistent electricity consumption, it can guarantee the hot weather cooling effect and cold weather heating effect.

In general, water source, ground source heat pump control system has two obvious advantages: first, seasonal conversion mode of work; second, water circulation flow demand and supply of automatic balance.

According to the heat pump technology, the water demand in the air conditioning system is generally controlled by the condition signal control method (see Fig. 1). The signal detection information is used to analyze the current condition of the whole system and adjust the corresponding control mode. Therefore, the method is efficient, easy to understand and less energy consumption.

Based on the heat pump technology, the operation flow of the air conditioning system is to detect the electromagnetic valve signal of each circuit through DDC, and to grasp the number of heat pump users in the system, and to obtain the heat pump utilization rate, so as to analyze the water flow in the water circulation unit. And then through the DDC to the inverter signal AO signal, and then control the pump speed, the actual water flow to adjust to the set value. In addition, based on the goal of increasing the accuracy of the system, it is necessary to check the water supply by the water flow sensor in the water circulation pipeline, and to control the running speed of the water pump and to balance the water supply amount and the output amount in comparison with the total water flow rate.

\section{Research on Energy-saving Control of AV}

Generally speaking, the air conditioning system control numerical changes. It is to change the air temperature

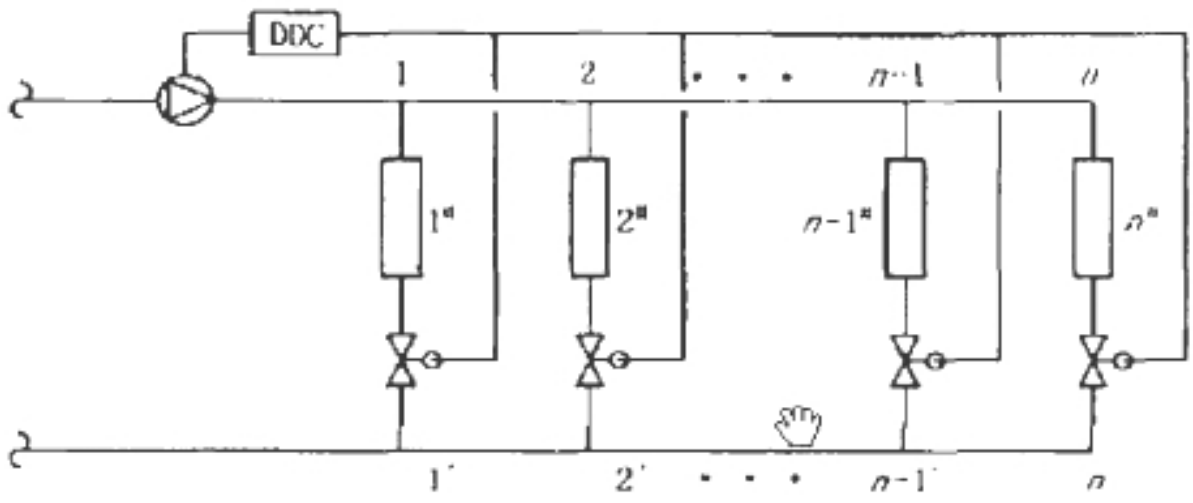

Figure 1 Heat pump unit operating signal control method of the schematic diagram 
or humidity to achieve, for example, the winter indoor temperature is lower than the standard temperature, then it will increase the air temperature, so that it increased to normal standards. Although the variable air volume system is different, but its' air supply temperature is relatively stable, generally control the air volume to change the control value. That is, when the indoor load changes or the set value changes, the system changes the speed of the blower unit by frequency change, adjusts the indoor air volume reasonably, and makes the parameters of the room reach the standard. VAV system is divided into two components: variable air volume control components and the end of the variable air volume, the specific operating principle shown in Figure 2 below.
VAV system control generally includes static pressure control mode and total air volume control mode. The former can be divided into static pressure control mode and dynamic static pressure control mode. Static pressure control mode is the sensor installed in the air volume of the static pressure at the minimum. It is to detect the static pressure and adjust the fan speed to ensure that the wind pressure is lower than the air flow pipe standard requirements; dynamic static pressure control mode is through the air volume sensor, temperature controller with the valve switch to adjust the fan speed. Compared with the former, the total air volume control method is based on the idea that the air flow rate and the total air volume at the end of the system are the same. The end wind fan replaces the air valve, combines the actual demand of the end,

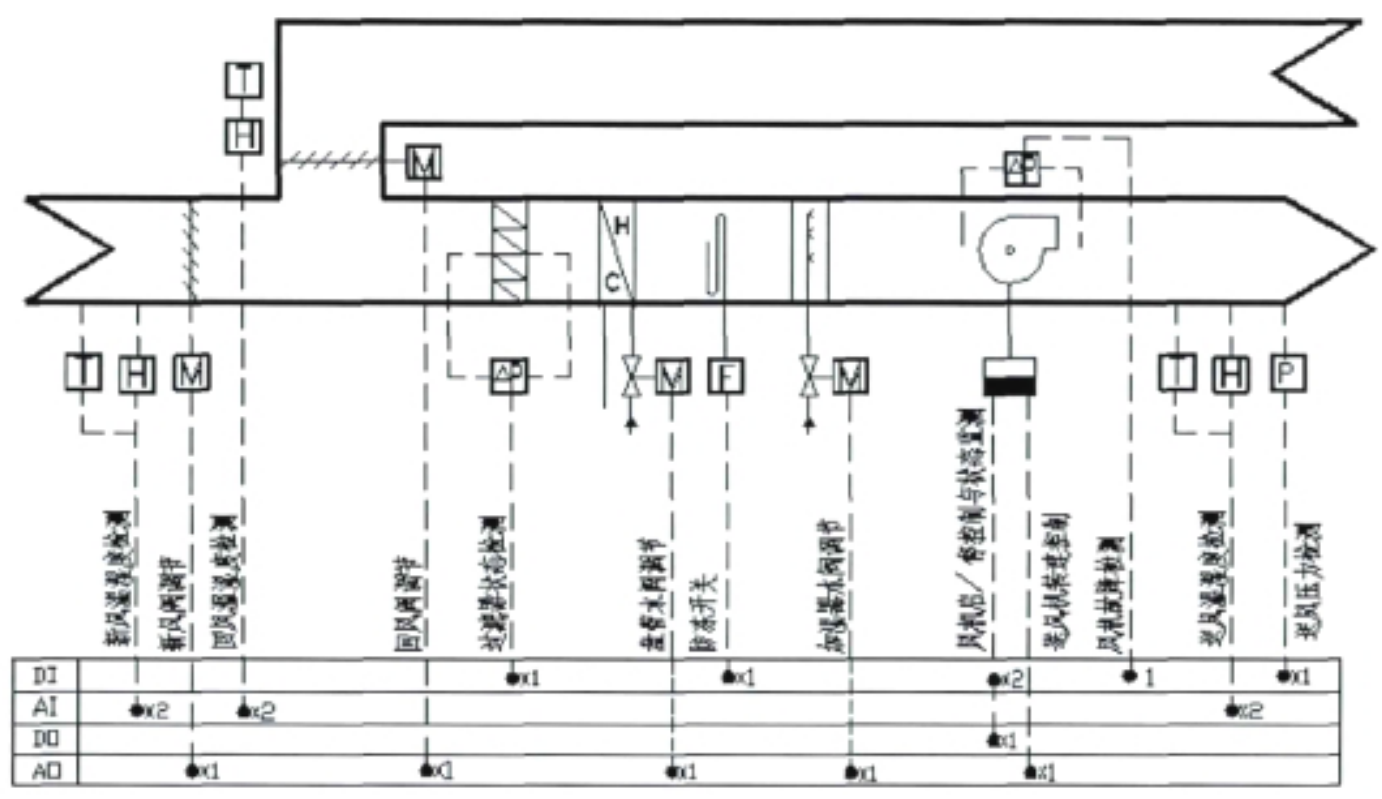

Figure 2 VAV system operating schematic diagram

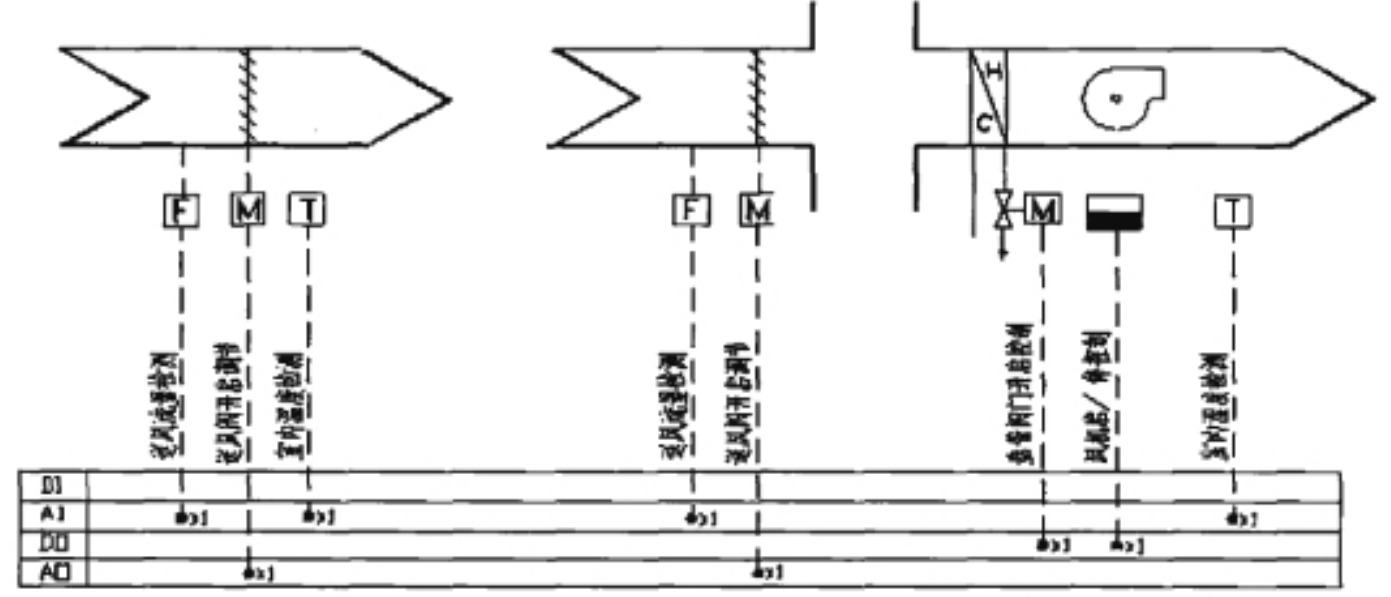

Figure 3 Single duct, tandem variable air volume system operating principle 
collects the analysis air volume data, and controls the running speed of the fan.

Single air duct, tandem variable air volume system operating schematic diagram below Figure 3 .

Compared with the traditional air volume system, the system has significant advantages:

Flexible aspects. For example, the office area in the office is different, and the number of personnel in the area and the degree of comfort are different. Compared with the constant air volume system, the system can meet the needs of the user through the regional control, and adjust the degree of the damper switch through the system end sensor, and then change the relevant parameter values.

$\square$ Less energy consumption. Combined with the above description, the user within the system with the specific needs of the set value, the system will adjust the cooling effect, the data show that the system because of the use of different conditions, the use of different time, there is no too high or too low temperature problems. Generally speaking, the overall cooling capacity by about $25 \%$, running less energy consumption.

\section{Study on energy-saving control of enthal}

The emergence and popularization of central air conditioning, while providing people comfortable and suitable environment, because of its operation, based on the goal of reducing energy consumption, often need to close the interior doors and windows, resulting in its internal air is not in circulation, the internal air quality is seriously reduced, the final resulting in similar air conditioning disease and other adverse circumstances. Especially after the end of SARS, more and more people are aware of the problem. Because the internal air enthalpy and the outside flow of air is quite different, if the maintenance and the flow of outside air, will greatly improve the energy consumption of air conditioning. It can be seen, with the new wind, return air and enthalpy energy-saving means, is an important means to solve this phenomenon.

Enthalpy refers to the amount of heat contained in the air, expressed as a function of air temperature and relative humidity. On the engineering point of view, once the specific air after treatment to make the enthalpy change, it shows that the heat contained in the fluctuations. If the enthalpy increases, indicating that the heat contained in the air increases; if the enthalpy decreases, indicating that the heat reduction.

In Figure 4, the specific work flow is: through the relevant air conditioning components to deal with the air

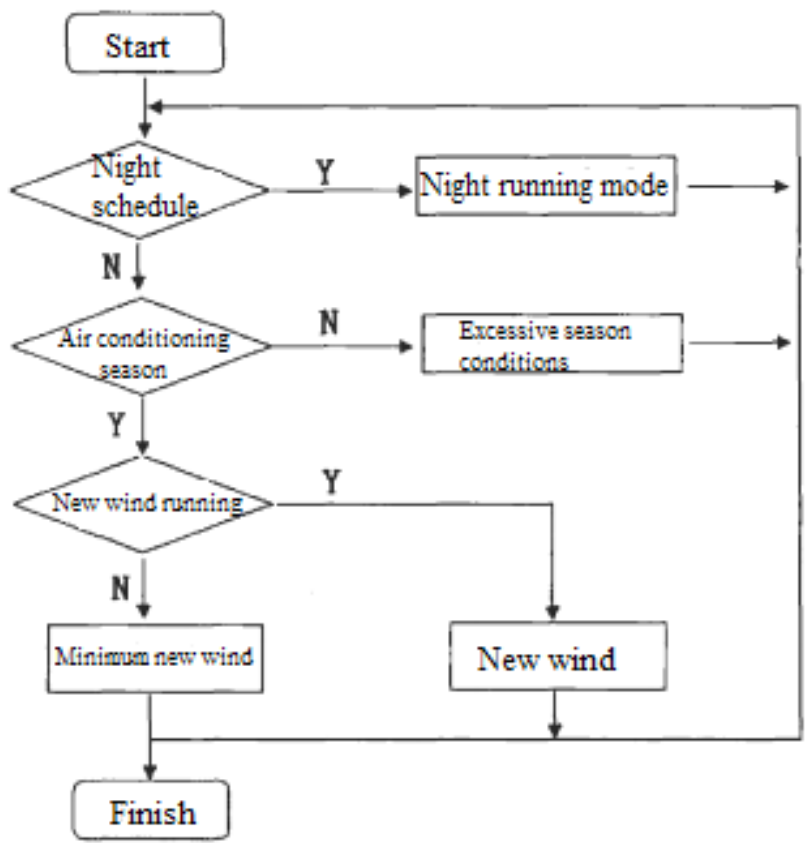

Figure 4 Enthalpy control work flow chart

According to the time changes set the night mode and the normal mode, in the climate appropriate evening, only control the input of new wind, which to reduce air conditioning energy consumption;

$\square$ Combined with indoor and outdoor enthalpy contrast, which to set the air conditioning season mode, control completely fresh or a few new wind;

Based on the goal of avoiding over-conversion of the air-conditioning season mode, the dead zone monitoring should be taken and the mode switching time should be specified, for example, every 30 minutes.

$\square$ Enthalpy judgments tend to have serious hysteresis, so most of them take Fuzzy-PID composite judgments. Its real-time dynamic feedback and high accuracy have been proven in the specific application.

\section{Research on Energy-saving Control of Light- ing System}

In the contemporary construction equipment, and air conditioning power consumption compared to the lighting system power consumption in hot pursuit, we can see, on the lighting system of energy control research cannot be ignored.

\subsection{Regional lighting}

Generally speaking, large-scale office buildings have conference rooms, office areas, gateways and other different regions, the various types of regional lighting control demand there is a difference, so to combine the regional characteristics or functions, the corresponding lighting control. In terms of an engineering point of 
view, the lighting system consists of a hallway corridor lighting, office area lighting, landscape obstruction lighting and emergency lighting four elements.

\subsection{Timing lighting}

For building electrical automation systems, designers can control the platform, combined with different lighting in the use of different times, which to improve the lighting time plan with a reasonable switch lighting. Such as office space after work off the office area of lighting.

\subsection{Intelligent lighting}

According to the above two points, we can find the building electrical automation system has the function of monitoring the lighting system, and is divided into regional monitoring and timing monitoring, but these two kinds of the monitoring mean for the special situation is still relatively rigid. For example, many employees now need to work overtime after getting off work, this time more flexible intelligent lighting system is more appropriate.

Now most of the intelligent lighting in accordance with Figure 5 bus structure:

Intelligent lighting system is generally embedded in the form of bus structure of the construction equipment automation system monitoring, through the building intelligent control platform for overall supervision and control.

\section{References}

[1] Zhou Yan. Based on the Intelligent Technology of Building Energy-Saving Facilities Design [J]. Automation and Instrumentation 2016 (04)

[2] Fu Dan. Intelligent Building Equipment Electrical
Automation System Design [J]. Heilongjiang Science and Technology Information .2013 (23)

[3] Liu Feng. Energy Saving and Optimization of Building Water Supply System [J]. Automation \& Instrumentation 2016 (04)

[4] LU Jian-bing. Design of Electrical Automation System for Intelligent Building Equipment [J]. Journal of Taiyuan Urban Vocational College 2012 (04)

[5] Lin Yihong. Intelligent Building Electrical Energy Saving and Energy Saving Design [J]. Automation and Instrumentation 2011 (03)

[6] Qin Wei. Analysis on the Problems of Installation of Electrical Automation System [J]. Enterprise Herald $.2011(11)$

[7] Xu Lili. Construction Engineering New Technology New Materials New Equipment Application Research [J]. Automation and Instrumentation 2014 (08)

[8] Wu Qing. Building Automation Control in the Hospital Application and Energy Saving [J]. Automation and Instrumentation 2016 (03)

[9] Zhang Jili, Zhao Tianyi, Chen Yongpan. LargeScale Public Air-Conditioning System Energy-Saving Control Research Progress [J]. Building Thermal Ventilation and Air Conditioning .2011 (03)

[10] Richard Everett ."Buliding Colleges for the Future "Program Delivering a Green and Intelligent Agenda. New Review of Information Network.2008

[11] Paul Allen.IT Basics for Energy Managers-The Evolution of Building Automation

[12] Jiang Ziyan. An Information Sharing Building Automation System. Intelligent Buildings International.2009

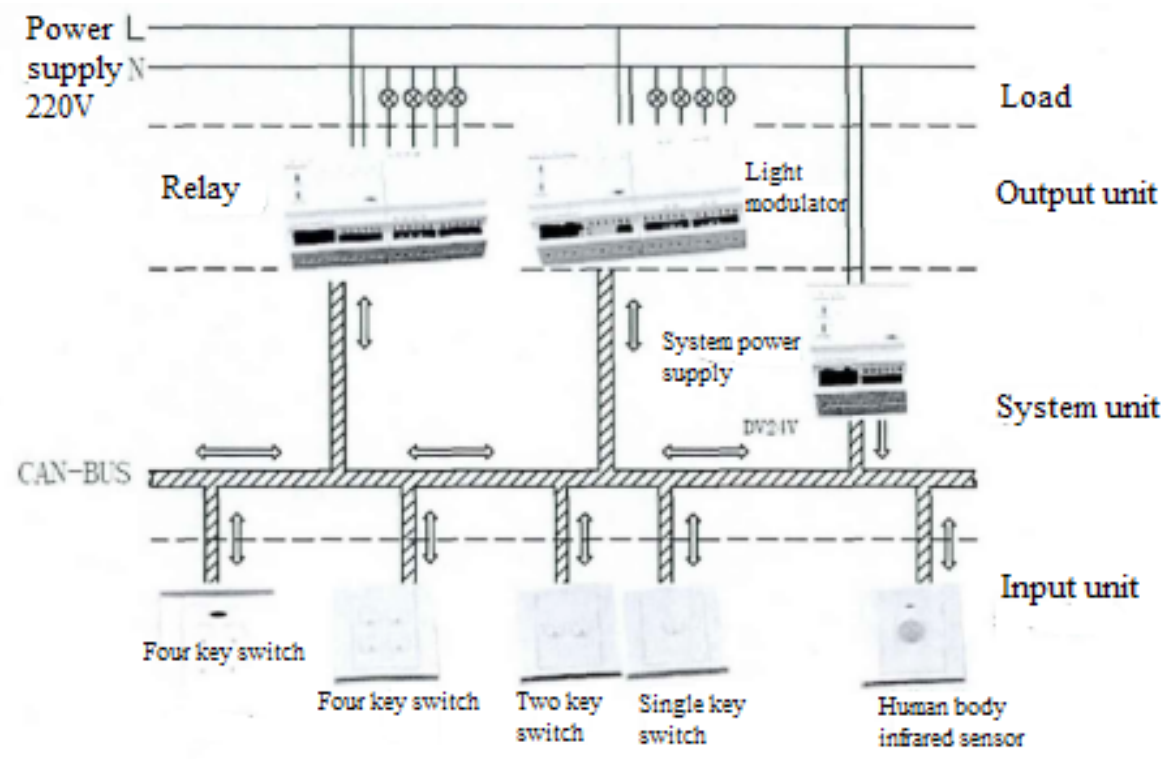

Figure 5 Intelligent lighting bus structure 